\title{
A INFLUÊNCIA DAS AÇÕES EDUCATIVAS NA GESTÃO DE PESSOAS DAS
}

\author{
INSTITUIÇÕES DE SAÚDE
}

\author{
Fernanda Maria de Miranda \\ Unimed São Carlos \\ fmdemirandap@gmail.com \\ Paola Lefcadito Alvares \\ Unimed São Carlos \\ palvares292@gmail.com \\ Carlos Eduardo Gatti Petroni \\ Centro Universitário Central Paulista (UNICEP) \\ gpetroni@gattipetroni.com.br \\ Recebido em: 16 abr. 2019 \\ Aceito em: 07 ago. 2019
}

Como citar este artigo: MIRANDA, Fernanda Maria de; ALVARES, Paola Lefcadito; PETRONI, Carlos Eduardo Gatti. A INFLUÊNCIA DAS AÇÕES EDUCATIVAS NA GESTÃO DE PESSOAS DAS INSTITUIÇÕES DE SAÚDE. Revista Visão: Gestão Organizacional, Caçador, SC, Brasil, p. 29-45, set. 2019. ISSN 2238-9636. Disponível em: <http://dx.doi.org/10.33362/visao.v8i2.1965>.

Resumo: Tendo em vista a importância da gestão de pessoas para as organizações de saúde brasileira e as recentes colaborações organizacionais para a criação e manutenção de ações educativas nestes cenários este estudo tem como objetivo identificar a influência da educação continuada em saúde (ECS) ou educação permanente em saúde (EPS) na Gestão de Pessoas nos Serviços de Saúde brasileiros. Trata-se de uma revisão integrativa da literatura de 22 artigos completos, das bases BDENF, SCIELO, LILACS e MEDLINE, publicados em português, a partir dos descritores controlados "Education, Continuing", "Personnel Management" e "Health". Foi possível identificar aumento da publicação científica sobre a temática e cinco núcleos de sentido, a saber: O foco da EPS é a pessoa que trabalha; O inefável Apoio Institucional; ECS/EPS como instrumento de Gestão; Políticas de Gestão de Pessoas; Emersão da Saúde do trabalhador através da EPS.

Palavras-Chave: Gestão de Pessoas. Educação Continuada. Serviços de Saúde.

THE INFLUENCE OF EDUCATIONAL ACTIONS IN HEALTH INSTITUTIONS PERSONNEL MANAGEMENT

Abstract: Considering the importance of personnel management for Brazilian health organizations and the recent organizational collaborations to create and maintain educational actions in these scenarios, this study aims to identify the influence of continuing education or permanent education in health personnel management in the Brazilian Health Services. It is an integrative literature review of 22 complete articles, from the databases BDENF, SCIELO, LILACS and MEDLINE, published in Portuguese, summarized from the controlled descriptions "Education, Continuing", "Personnel Management" and "Health". It was identified an increase in the scientific publication on 
this subject and five nuclei of meaning, called: The focus of EPS is the work person; The ineffable Institutional Support; ECS/EPS as a management tool; Personnel Management Policies; Emersion of Workers' Health through EPS.

Keywords: Education Continuing. Personnel Management. Health Services.

\section{INTRODUÇÃO}

A educação continuada é entendida como o conjunto de atividades educativas que objetivam a capacitação profissional (SARDINHA PEIXOTO et al, 2013), sendo um processo (MOTA LINO et al, 2007, p.77):

(...) educativo, formal ou informal, dinâmico, dialógico e contínuo, de revitalização e superação pessoal e profissional, de modo individual e coletivo, buscando qualificação, postura ética, exercício da cidadania, conscientização, reafirmação ou reformulação de valores, construindo relações integradoras entre os sujeitos envolvidos para uma práxis crítica e criadora.

De outro ponto de vista, a educação continuada em saúde (ECS) é também compreendida como "processo de aquisição sequencial e acumulativa de informações técnicocientíficas pelo trabalhador, por meio de escolarização formal, de vivências, de experiências laborais e de participação no âmbito institucional ou fora dele" (BRASIL, 2009, s/p). Ou seja, todos os processos educativos formais ou informais que são realizados após a titulação determinante de um cargo ou função podem ser entendidos como parte da educação continuada.

Já o conceito de Educação Permanente em Saúde (EPS) surge em 1978 com a Organização Pan-Americana de Saúde (OPAS) e se consolidou no Brasil em 2003 com o lançamento da Política Nacional de Educação Permanente em Saúde (SARDINHA PEIXOTO et al, 2013) e é compreendido como um projeto político-didático-pedagógico.

Trata-se de contextualizar a aprendizagem no contexto de trabalho, partindo da problematização da própria prática profissional como motriz para a aprendizagem (SARDINHA PEIXOTO et al, 2013).

Nas Organizações de saúde, públicas e privadas, esforços são observados para que o desenvolvimento dos colaboradores seja visto como estratégico e garantido pela Organização, sendo comum a existência de setores ligados à Gestão de Pessoas para organizar o trabalho educativo de educação continuada e/ou permanente em saúde.

Dentro da concepção de educação na saúde, ações educativas voltadas para as equipes multiprofissionais trazem benefícios diretos para a qualidade da assistência prestada (FALKENBERG, 2014). Além disso, a educação dentro do próprio processo de trabalho garante a aquisição de conhecimento dos profissionais, através de ações direcionadas à qualificação dos processos de trabalho em saúde, às especificidades locais e às necessidades do trabalho 
real (FALKENBERG, 2014).

Neste sentido, passou a fazer parte da Gestão de Pessoas dos Serviços de Saúde a preocupação com as ações de educação continuada e/ou permanente em saúde e seus resultados para o desenvolvimento do colaborador.

Dentro do campo da administração, a concepção atual de gestão de pessoas surge, quando na era da informação as pessoas e, consequentemente, suas competências passam a integrar a base da organização (SANTOS; FRANCO, 2018). Com papel estratégico, as pessoas são compreendidas como agregadoras de valor na instituição e sua valorização se torna imprescindível para o sucesso organizacional (SANTOS; FRANCO, 2018). Neste cenário, são envolvidos como substratos dos processos de desenvolvimento os treinamentos, desenvolvimento de pessoas e desenvolvimento organizacional.

É compreensível que as ações resultantes dos programas de educação continuada e/ou permanente nos serviços de saúde podem influenciar nas decisões estratégicas para a Gestão de Pessoas. Porém, não há estudos que se debruçam neste viés para o contexto das Organizações de saúde brasileiras. Desta forma, objetivou-se com este estudo identificar a influência da educação continuada ou educação permanente em saúde na Gestão de Pessoas nos Serviços de Saúde brasileiros.

\section{MATERIAL E MÉTODO}

A metodologia de revisão integrativa da literatura foi utilizada neste estudo. Este tipo de revisão objetiva à definição de conceitos, revisão de teorias e evidências ou análise de problemas metodológicos de um tópico particular (WHITTEMORE; KNAFL, 2005). Esta escolha se concretizou considerando a necessidade de se combinar dados da literatura teórica e empírica, mesclando assim estudos experimentais e não-experimentais para uma compreensão completa do fenômeno analisado (WHITTEMORE; KNAFL, 2005).

Este tipo de revisão segue seis etapas sequenciais e distintas validadas na literatura, sendo iniciada com a identificação do tema e seleção da hipótese ou questão de pesquisa, seguindo com o estabelecimento de critérios de inclusão e exclusão dos estudos e busca na literatura, definição das informações a serem extraídas dos estudos selecionados, avaliação dos estudos inclusos, interpretação dos resultados e, finalmente, a apresentação da revisão (MENDES; SILVEIRA; GALVÃO, 2008).

Para guiar a seleção dos artigos, a busca se baseou na questão: Qual a influência da educação ECS ou EPS na Gestão de Pessoas no contexto dos serviços de saúde?

Visando abranger a maior quantidade de estudos relevantes sobre a temática, optouse por utilizar os descritores controlados "Education, Continuing", "Personnel Management" e "Health" da lista de descritores Medical Subject Headings (MeSH), sendo os descritores 
utilizados nas buscas em conjunto com o booleano AND. Foram utilizadas as bases de dados Scientific Electronic Library Online (SciELO), Literatura Latino-Americana e do Caribe em Ciências da Saúde (LILACS), Base de Dados de Enfermagem (BDENF) e Medical Literature Analysis and Retrieval System Online (MEDLINE).

Para contemplar os objetivos desta investigação foram utilizados os seguintes critérios de seleção: artigos publicados em português e disponibilizados na íntegra. Foram excluídas as revisões de literatura ou publicações secundárias como livros, teses e dissertações, aqueles realizados com outros sujeitos de investigação. Além disso, para ser considerado elegível, o estudo deveria também explicitar em seu título e/ou resumo a relação com a temática da pesquisa.

A busca na literatura foi realizada por dois pesquisadores separadamente, a fim de evitar viés na seleção dos artigos. Para isso, foi construído um protocolo identificando os passos a serem seguidos e este criteriosamente utilizado pelos pesquisadores durante a fase de busca.

A seguir os achados foram confrontados e o grau de concordância foi analisado a partir do Teste de Concordância Kappa (MCHUGH, 2012). Neste contexto, os valores maiores que 0,75 representam excelente grau de concordância entre os pesquisadores, os situados entre 0,40 e 0,75 representam concordância mediana e os abaixo de 0,40 representam baixa concordância (MCHUGH, 2012). Em seguida, os artigos discrepantes na análise foram reavaliados em conjunto pelos dois pesquisadores buscando-se o consenso.

Para extração de dados foi utilizada uma matriz baseada nos requisitos do instrumento Preferred Reporting Items for Systematic Reviews and Meta-Analysis (PRISMA), contendo: fonte de publicação (autores, título, ano de publicação, revista, volume, número e página), informações adicionais (financiamento, resumo, categoria de análise, país de origem, tipo de artigo), introdução (lógica, objetivos, lacunas), métodos (tipo de estudo e principais características), resultados e conclusões (MOHER et al., 2009). Por fim, os dados devidamente categorizados foram confrontados entre si e com o referencial teórico pertinente.

\section{RESULTADOS E DISCUSSÃO}

Após a pesquisa nos bancos de dados delimitados, foram selecionadas 7087 referências bibliográficas. Os dados encontrados foram submetidos ao protocolo de busca pelos dois pesquisadores originando os resultados expressos pela Tabela 1. 
Tabela 1 - Artigos encontrados no processo de busca segundo pesquisador. São Carlos, 2019.

\begin{tabular}{|c|c|c|c|c|c|c|c|c|c|}
\hline \multirow[t]{2}{*}{ Busca } & \multirow[t]{2}{*}{ Total } & \multirow[t]{2}{*}{$\begin{array}{l}\text { Filtro: } \\
\text { idioma }\end{array}$} & \multirow[t]{2}{*}{$\begin{array}{l}\text { Filtro: } \\
\text { tipo }\end{array}$} & \multicolumn{2}{|c|}{$\begin{array}{l}\text { Seleção } \\
\text { temática }\end{array}$} & \multicolumn{2}{|c|}{$\begin{array}{c}\text { Filtro: } \\
\text { duplicados }\end{array}$} & \multicolumn{2}{|c|}{$\begin{array}{c}\text { Filtro: } \\
\text { Disponíveis/ } \\
\text { Primários }\end{array}$} \\
\hline & & & & P1 & P2 & P1 & P2 & P1 & P2 \\
\hline SciELO & 42 & 40 & 40 & 12 & 14 & 12 & 13 & 10 & 11 \\
\hline BDENF & 19 & 19 & 18 & 08 & 11 & 07 & 10 & 06 & 08 \\
\hline LILACS & 151 & 92 & 58 & 16 & 12 & 08 & 06 & 05 & 04 \\
\hline MEDLINE & 6875 & 26 & 26 & 04 & 04 & 01 & 01 & 01 & 01 \\
\hline Total & 7087 & 177 & 142 & 40 & 40 & 28 & 30 & 22 & 24 \\
\hline
\end{tabular}

Após a aplicação dos filtros de idioma e tipo, os 142 artigos encontrados foram selecionados por cada pesquisador separadamente, sendo identificadas 24 referencias bibliográficas após a leitura de título e resumos. Tais artigos foram categorizadas acerca da aceitação ou rejeição segundo pesquisador para realização do cálculo do Grau de Concordância Kappa (Tabela 2):

Tabela 2 - Classificação dos artigos segundo pesquisador. São Carlos, 2019.

\section{Pesquisador 2}

\begin{tabular}{l|l|l}
\cline { 2 - 3 } & Pesquisador 1 & \\
\cline { 2 - 3 } & Aceitar & Rejeitar \\
\hline Aceitar & 21 & 03 \\
\hline Rejeitar & 01 & 116 \\
\hline
\end{tabular}

A concordância entre ambos pesquisadores foi de 0,87 , ou seja, excelente grau de concordância (MCHUGH, 2012). Os três artigos discrepantes entre os pesquisadores foram reavaliados e após consenso foi aplicado o critério de seleção "disponível na íntegra", obtendose a amostra de 22 artigos nesta revisão de literatura. A caracterização dos artigos inclusos está exposta na Figura 1.

Figura 1 - Caracterização dos estudos incluídos na revisão. São Carlos, 2019.

\begin{tabular}{l|l|l|l}
\hline N & Nome & Objetivo & Design \\
\hline A1 & $\begin{array}{l}\text { The Pororoca effect on permanent } \\
\text { education in health: about the interaction } \\
\text { research-work (FIGUEIREDO et al, 2018). }\end{array}$ & $\begin{array}{l}\text { Construir responsabilidade municipal } \\
\text { com a política de EPS a partir da } \\
\text { interação entre práticas de pesquisa } \\
\text { e inovação no trabalho. }\end{array}$ & $\begin{array}{l}\text { Qualitativo - } \\
\text { Relato de } \\
\text { Experiência }\end{array}$ \\
\hline A2 & $\begin{array}{l}\text { Implementação do Programa de Melhoria } \\
\text { do Acesso e Qualidade segundo gestores } \\
\text { da Atenção Básica de São Paulo (COELHO } \\
\text { E SILVA, 2017). }\end{array}$ & $\begin{array}{l}\text { Analisar a implementação do PMAQ } \\
\text { segundo gerentes de Unidades } \\
\text { Básicas de Saúde. }\end{array}$ & $\begin{array}{l}\text { Qualitativo } \\
\text { exploratório - } \\
\text { História Oral }\end{array}$ \\
\hline A3 & $\begin{array}{l}\text { O modelo pedagógico da universidade } \\
\text { aberta do sus e o seu alinhamento com a } \\
\text { educação permanente e as competências } \\
\text { profissionais em saúde (BRASIL; HADDAD, } \\
\text { 2017). }\end{array}$ & $\begin{array}{l}\text { Identificar e analisar, no modelo } \\
\text { pedagógico, os marcos conceituais } \\
\text { que apóiam o desenvolvimento das } \\
\text { ações educacionais do Sistema UNA- } \\
\text { SUS. }\end{array}$ & $\begin{array}{l}\text { Análise } \\
\text { Documental }\end{array}$ \\
\hline A4 & $\begin{array}{l}\text { Gestão hospitalar e educação } \\
\text { permanente: um estudo descritivo e }\end{array}$ & $\begin{array}{l}\text { Investigar a Educação Permanente } \\
\text { em Saúde como ferramenta de }\end{array}$ & $\begin{array}{l}\text { Qualitativo - } \\
\text { Análise }\end{array}$ \\
\hline
\end{tabular}




\begin{tabular}{|c|c|c|c|}
\hline & exploratório (MEDEIROS; GOUVÊA, 2017). & $\begin{array}{l}\text { gestão em um centro cirúrgico de } \\
\text { um hospital público universitário de } \\
\text { grande porte, situado no município } \\
\text { do Rio de Janeiro. Contribuir para a } \\
\text { reflexão sobre ações educativas } \\
\text { dirigidas aos trabalhadores, com } \\
\text { enfoque na gestão hospitalar. }\end{array}$ & $\begin{array}{l}\text { Temática de } \\
\text { Conteúdo }\end{array}$ \\
\hline A5 & $\begin{array}{l}\text { Gestão hospitalar como ferramenta do } \\
\text { cuidado (ADORNO et al, 2017). }\end{array}$ & $\begin{array}{l}\text { Analisar os processos promotores de } \\
\text { humanização no gerenciamento de } \\
\text { recursos } \\
\text { humanos, segundo a percepção da } \\
\text { equipe de Enfermagem. }\end{array}$ & $\begin{array}{l}\text { Qualitativo - } \\
\text { Análise } \\
\text { Temática de } \\
\text { Conteúdo }\end{array}$ \\
\hline A6 & $\begin{array}{l}\text { A inserção da universidade no quadrilátero } \\
\text { da educação permanente em saúde: } \\
\text { relato de experiência (VENDRUSCOL et al, } \\
\text { 2016). }\end{array}$ & $\begin{array}{l}\text { Apresentar a experiência de uma } \\
\text { universidade pública, com } \\
\text { representação junto ao Centro de } \\
\text { Integração de Educação e Saúde } \\
\text { (CIES) da Macrorregião } \\
\text { Oeste de Santa Catarina, na } \\
\text { participação e articulação da } \\
\text { Comissão, entre os anos de } 2011 \text { e } \\
\text { 2013. }\end{array}$ & $\begin{array}{l}\text { Qualitativo- } \\
\text { Relato de } \\
\text { Experiência }\end{array}$ \\
\hline A7 & $\begin{array}{l}\text { Perspectiva dos gestores de uma região do } \\
\text { estado de São Paulo sobre educação } \\
\text { permanente em saúde (MISHIMA et al, } \\
\text { 2015). }\end{array}$ & $\begin{array}{l}\text { Identificar e analisar os conceitos de } \\
\text { EPS, operados pelos gestores } \\
\text { municipais de saúde ou } \\
\text { coordenadores da Atenção Básica } \\
\text { (AB) da região de abrangência de um } \\
\text { Departamento Regional de Saúde do } \\
\text { nordeste do estado de São Paulo - } \\
\text { Brasil. }\end{array}$ & $\begin{array}{l}\text { Qualitativo } \\
\text { Descritivo } \\
\text { Exploratório }\end{array}$ \\
\hline A8 & $\begin{array}{l}\text { Desafios à gestão do trabalho e educação } \\
\text { permanente em saúde para a produção do } \\
\text { cuidado na estratégia saúde da família } \\
\text { (SANTOS et al, 2015). }\end{array}$ & $\begin{array}{l}\text { Analisar a gestão do trabalho e a } \\
\text { educação permanente em saúde. } \\
\text { Analisar as atividades desenvolvidas } \\
\text { por equipes de Saúde da Família } \\
\text { relacionadas ao cuidado e à } \\
\text { educação em saúde, em um } \\
\text { município da Macrorregião } \\
\text { Sudoeste da Bahia. }\end{array}$ & $\begin{array}{l}\text { Quantitativo- } \\
\text { Estudo de Caso }\end{array}$ \\
\hline A9 & $\begin{array}{l}\text { Educação Permanente no cotidiano da } \\
\text { Atenção Básica no Mato Grosso do Sul } \\
\text { (MACHADO et al, 2015). }\end{array}$ & $\begin{array}{l}\text { Analisar a prevalência e as } \\
\text { características das ações de } \\
\text { Educação Permanente e as ações de } \\
\text { planejamento e de gestão em } \\
\text { interface com a Educação } \\
\text { Permanente em Saúde (EPS), no } \\
\text { cotidiano da AB, no Estado de Mato } \\
\text { Grosso do Sul, a partir dos dados } \\
\text { revelados pela Avaliação Externa do } \\
\text { PMAQ ciclo } 1 .\end{array}$ & $\begin{array}{l}\text { Quantitativo- } \\
\text { observacional } \\
\text { analítico } \\
\text { transversal }\end{array}$ \\
\hline A10 & $\begin{array}{l}\text { Educação permanente em saúde segundo } \\
\text { os profissionais da gestão de Recife, } \\
\text { Pernambuco (LIMA; ALBUQUERQUE; } \\
\text { WENCESLAU, 2014). }\end{array}$ & $\begin{array}{l}\text { Discutir o que pensam os } \\
\text { profissionais da gestão sobre os } \\
\text { processos de educação } \\
\text { permanente em saúde no município } \\
\text { de Recife, Pernambuco, descrevendo } \\
\text { as ações e relacionando-as com os } \\
\text { conceitos de educação permanente }\end{array}$ & $\begin{array}{l}\text { Qualitativo - } \\
\text { Análise de } \\
\text { Conteúdo }\end{array}$ \\
\hline
\end{tabular}




\begin{tabular}{|c|c|c|c|}
\hline & & ou continuada. & \\
\hline A11 & $\begin{array}{l}\text { Desenvolvimento de recursos humanos } \\
\text { para atuar nos serviços de saúde mental } \\
\text { (SILVA et al, 2013). }\end{array}$ & $\begin{array}{l}\text { Compreender os aspectos } \\
\text { relacionados à formação } \\
\text { e capacitação dos profissionais que } \\
\text { atuam nos serviços de saúde mental } \\
\text { no interior do Estado de } \\
\text { Goiás, Brasil, sob o ponto de vista } \\
\text { dos coordenadores destes serviços. }\end{array}$ & $\begin{array}{l}\text { Qualitativo - } \\
\text { Análise } \\
\text { Temática de } \\
\text { Conteúdo }\end{array}$ \\
\hline A12 & $\begin{array}{l}\text { Gestão de recursos financeiros da } \\
\text { educação permanente em saúde: desafio } \\
\text { das comissões de integração ensino- } \\
\text { serviço (FERRAZ et al, 2013). }\end{array}$ & $\begin{array}{l}\text { Discutir as potencialidades e as } \\
\text { fragilidades vivenciadas em cada } \\
\text { CIES, bem como destacar a forma } \\
\text { como os participantes } \\
\text { dialogicamente se organizam para } \\
\text { buscar soluções aos problemas do } \\
\text { manejo dos recursos financeiros da } \\
\text { EPS. }\end{array}$ & $\begin{array}{l}\text { Qualitativo - } \\
\text { Pesquisa } \\
\text { Participante }\end{array}$ \\
\hline A13 & $\begin{array}{l}\text { Compreensão dos coordenadores de } \\
\text { serviços de saúde sobre educação } \\
\text { permanente (DUARTE; OLIVEIRA, 2012). }\end{array}$ & $\begin{array}{l}\text { Compreender o conhecimento dos } \\
\text { coordenadores dos Serviços de } \\
\text { Saúde sobre a Educação Permanente } \\
\text { e identificar os principais desafios na } \\
\text { implantação dessa política no } \\
\text { município }\end{array}$ & $\begin{array}{l}\text { Qualitativo - } \\
\text { Análise } \\
\text { Temática de } \\
\text { Conteúdo }\end{array}$ \\
\hline A14 & $\begin{array}{l}\text { "Rodas de educação permanente" na } \\
\text { atenção básica de saúde: analisando } \\
\text { contribuições (CARDOSO, 2012). }\end{array}$ & $\begin{array}{l}\text { Analisar a contribuição das Rodas de } \\
\text { Educação Permanente na } \\
\text { transformação das práticas de saúde } \\
\text { na rede de Atenção Básica da } \\
\text { Secretaria Municipal de Saúde de } \\
\text { Vitória. }\end{array}$ & Não explicitado \\
\hline A15 & $\begin{array}{l}\text { Custo de educação continuada para } \\
\text { equipe de enfermagem de um hospital } \\
\text { universitário público (COSTA et al, 2012). }\end{array}$ & $\begin{array}{l}\text { Determinar o custo direto e indireto } \\
\text { dos treinamentos de educação } \\
\text { continuada realizados para a equipe } \\
\text { de enfermagem. }\end{array}$ & $\begin{array}{l}\text { Quantitativo- } \\
\text { Descritivo } \\
\text { transversal }\end{array}$ \\
\hline A16 & $\begin{array}{l}\text { Necessidades e dificuldades de tutores e } \\
\text { facilitadores para implementar a política } \\
\text { de educação permanente em saúde em } \\
\text { um município de grande porte no estado } \\
\text { do Paraná, Brasil (MENDONZA; NUNES, } \\
\text { 2011). }\end{array}$ & $\begin{array}{l}\text { Investigar quais as necessidades e } \\
\text { dificuldades vivenciadas por tutores } \\
\text { e facilitadores de } \\
\text { educação permanente em saúde no } \\
\text { Município de Londrina, PR. }\end{array}$ & $\begin{array}{l}\text { Qualitativo - } \\
\text { Análise de } \\
\text { Discurso }\end{array}$ \\
\hline A17 & $\begin{array}{l}\text { Educação permanente em saúde: } \\
\text { atribuições e deliberações à luz da Política } \\
\text { Nacional e do Pacto de Gestão (ANDRADE; } \\
\text { MEIRELLES; LAZONI, 2011). }\end{array}$ & $\begin{array}{l}\text { Analisar, comparativamente entre os } \\
\text { gestores de saúde, a estruturação } \\
\text { estabelecida no âmbito da Educação } \\
\text { em Saúde e a evolução da } \\
\text { organização, articulação e pactuação } \\
\text { das diretrizes da Política de } \\
\text { Educação Permanente em Saúde. }\end{array}$ & $\begin{array}{l}\text { Qualitativo - } \\
\text { Análise } \\
\text { Documental }\end{array}$ \\
\hline A18 & $\begin{array}{l}\text { Indicadores de qualidade no } \\
\text { gerenciamento de recursos humanos em } \\
\text { enfermagem: elementos constitutivos } \\
\text { segundo percepção de enfermeiros } \\
\text { (VIEIRA; KURCGANT, 2010). }\end{array}$ & $\begin{array}{l}\text { Analisar os significados que os } \\
\text { enfermeiros atribuem aos } \\
\text { indicadores de qualidade de } \\
\text { gerenciamento de recursos } \\
\text { humanos e resgatar os elementos de } \\
\text { essencialidade constitutivos do } \\
\text { processo de gerenciamento de } \\
\text { recursos humanos para a construção } \\
\text { de indicadores de avaliação em }\end{array}$ & $\begin{array}{l}\text { Qualitativo - } \\
\text { Análise } \\
\text { Temática de } \\
\text { Conteúdo }\end{array}$ \\
\hline
\end{tabular}




\begin{tabular}{|c|c|c|c|}
\hline & & saúde. & \\
\hline A19 & $\begin{array}{l}\text { Indicadores de qualidade no } \\
\text { gerenciamento de recursos humanos em } \\
\text { enfermagem (LIMA; KURCGANT, 2009). }\end{array}$ & $\begin{array}{l}\text { Identificar os elementos } \\
\text { constitutivos de indicadores de } \\
\text { qualidade de gerenciamento de RH } \\
\text { em Enfermagem segundo a } \\
\text { percepção de enfermeiras de um } \\
\text { Hospital Universitário. }\end{array}$ & $\begin{array}{l}\text { Qualitativo - } \\
\text { Análise } \\
\text { Temática de } \\
\text { Conteúdo }\end{array}$ \\
\hline $\mathrm{A} 20$ & $\begin{array}{l}\text { Diagnóstico da situação dos trabalhadores } \\
\text { em saúde e o processo de Formação no } \\
\text { polo regional de educação permanente } \\
\text { em saúde (MUROFUSE et al, 2009). }\end{array}$ & $\begin{array}{l}\text { Realizar levantamento da situação } \\
\text { dos profissionais de saúde que } \\
\text { atuam na rede de serviços públicos } \\
\text { dos municípios de abrangência da } \\
\text { 10a regional de saúde e identificar as } \\
\text { atividades de formação } \\
\text { frequentadas entre } 2004 \text { e } 2006 \text {. }\end{array}$ & $\begin{array}{l}\text { Misto - Análise } \\
\text { Temática e } \\
\text { estatística } \\
\text { simples }\end{array}$ \\
\hline $\mathrm{A} 21$ & $\begin{array}{l}\text { Educação permanente no trabalho como } \\
\text { um processo educativo e cuidativo do } \\
\text { sujeito-cuidador (FERRAZ et al, 2006). }\end{array}$ & $\begin{array}{l}\text { Refletir sobre a perspectiva da } \\
\text { educação permanente no trabalho } \\
\text { como uma forma de cuidado do } \\
\text { sujeito-cuidador. }\end{array}$ & $\begin{array}{l}\text { Qualitativo - } \\
\text { Artigo de } \\
\text { Reflexão }\end{array}$ \\
\hline $\mathrm{A} 22$ & $\begin{array}{l}\text { Formação permanente, flexível e a } \\
\text { distância pela Internet: Curso de Gestão } \\
\text { Descentralizada de Recursos Humanos em } \\
\text { Saúde (STRUCHINER; ROSCHKE; RICCIARDI, } \\
\text { 2002). }\end{array}$ & $\begin{array}{l}\text { Descreve o Curso de Gestão } \\
\text { Descentralizada de Recursos } \\
\text { Humanos em Saúde, um programa } \\
\text { de educação a distância baseado na } \\
\text { Internet para a formação e a } \\
\text { educação continuada de } \\
\text { profissionais de saúde. }\end{array}$ & Qualitativo \\
\hline
\end{tabular}

Embora não se tenha utilizado como determinante a data de publicação do artigo como critério de seleção, tem-se observado um discreto aumento da produção científica sobre a temática, conforme expressa o gráfico 1.

Figura 2 - Distribuição dos artigos selecionados por ano de publicação. São Carlos, 2019.

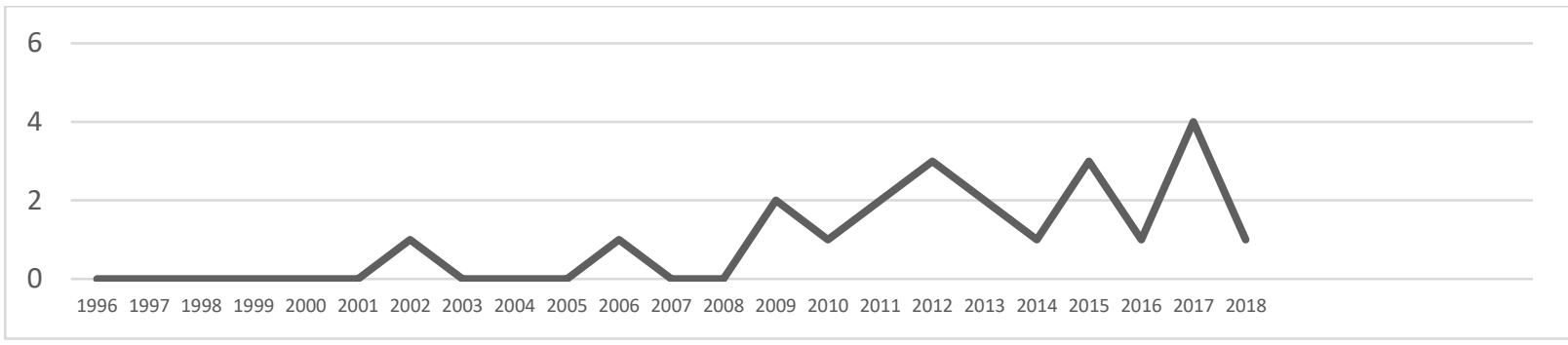

Observou-se ainda que todos os trabalhos expressavam um nível de evidência semelhante, sendo que as pesquisas realizadas descreviam um único estudo descritivo ou qualitativo, ou seja, apresentavam o nível 6 de evidência segundo a classificação de Melnyk e Fineout-Overholt (2005). Desta forma, no que tange o método de pesquisa, foram encontradas pesquisas quantitativas e qualitativas com relação a forma de abordagem do problema, na proporção abaixo (Gráfico 2). 
Figura 3 - Distribuição dos estudos segundo forma de abordagem do problema. São Carlos. 2019.

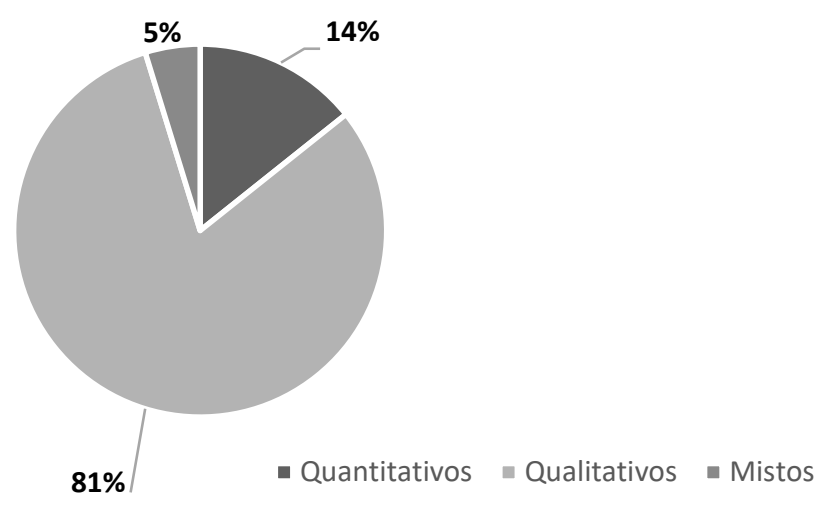

Com relação aos designs, foram mais numerosos os estudos descritivos exploratórios tanto no viés quantitativo, através de utilização de estatística simples para análise dos dados, quanto no viés qualitativo, através da análise temática de conteúdo.

As diferenças teóricas dos conceitos entre EPS e ECS foram discutidos nas pesquisas da amostra, porém ainda há dificuldade em limitar os achados relacionados à EPS e ECS em categorias distintas. Dos estudos selecionados, um versava especificamente sobre ECS [A15], quinze versavam sobre EPS [A1, A3, A4, A6-A10, A12-A14, A16, A17, A20 e A21]. Os demais estudos traziam a ECS/EPS como parte integrante dos achados acerca da gestão em saúde e qualidade, embora não fosse o enfoque do estudo [A2, A5, A11, A18, A19 e A22].

Desta maneira, nesta revisão integrativa da literatura, embora não se utilize ECS e EPS como sinônimos, entende-se que os termos são complementares e sua influência na Gestão de Pessoas não precisa ser categorizada entre as modalidades.

Após a extração de dados, no sentido de identificar a influência da educação continuada e/ou permanente em saúde para a Gestão de Pessoas nas Instituições de Saúde, foram observados cinco eixos temáticos, a partir dos núcleos de sentido encontrados, a se saber: a) O foco da EPS é a pessoa que trabalha; b) O inefável Apoio Institucional; c) ECS/EPS como instrumento de Gestão; d) Políticas de Gestão de Pessoas; e) Emersão da Saúde do trabalhador através da EPS.

\section{O FOCO DA EPS É A PESSOA QUE TRABALHA}

Dentro da concepção de EPS a afirmação de um sujeito, trabalhador, autônomo, crítico e reflexivo está consolidada. Para tanto, a EPS estabelece princípios dialéticos e geradores de autonomia a partir da concepção da pedagogia freireana [A9]. Neste sentido, Figueiredo et al [A1] ressalta que é necessário deixar o significado das representações da profissão para deixar emergir o sujeito escondido em cada trabalhador. O interesse da EPS está, então, nas "pessoas, em suas marcas e inacabamentos, em uma formação desformadora, cujo saber se produziria a partir do saber-se inacabado e da visão crítica sobre si e sobre o outro 
como sujeito imperfeito e falível" (FIGUEIREDO et al, 2017, p.1876).

Desta forma, torna-se função da EPS instrumentalizar a formação deste sujeitocuidador, o compreendendo como "um ser humano, um 'ser' de relações consigo, com o outro e com o mundo, num processo contínuo e dinâmico de cuidar, ensinar, aprender, construir, desconstruir, reconstruir e interagir" (FERRAZ et al, 2006, p. 346).

O contexto de trabalho não é apenas coincidente na construção do foco da EPS. Ele permeia a influência da educação na Gestão de Pessoas, na medida em que, qualifica este sujeito trabalhador. É nas Instituições de Saúde que são produzidas as relações, tornando este espaço tão favorável para o processo de aprendizagem do trabalhador [A1, A10].

Dentro do contexto educativo das iniciativas de ECS e EPS torna-se evidente seu objetivo de contribuir no processo gerencial descrito na Gestão de pessoas (BRASIL, 2009; SANTOS; FRANCO, 2018). Estes processos educativos, dinâmicos e contínuos, buscam promover avanços sociais, capacitação e qualificação de pessoas [A5, A6, A7, A11], aumentando seu poder de resolutividade, além de incremento de resultados [A7].

Desta forma, a EPS torna-se potente para qualificar os segmentos da gestão, atenção e controle social no contexto do Sistema Único de Saúde (SUS), extrapolando o significado do desenvolvimento de pessoas para o próprio desenvolvimento da Instituição [A9].

\section{O INEFÁVEL APOIO ORGANIZACIONAL}

O apoio organizacional emergiu em grande parte dos estudos como fator fundamental para a construção de espaços de ECS/EPS [A1, A2, A6, A9, A16, A18, A19]. Mas o que é compreendido como apoio organizacional nestes estudos?

Este vínculo surge sob diferentes olhares e perspectivas, com destaque para a necessidade do caminhar conjunto entre a EPS e o apoio dado pela instituição [A2], buscando garantir lugar institucional para estas ações [A1, A16]. Acerca da relação entre o sucesso das ações e o apoio da Gestão, Mendonça e Nunes [A16] destacam que:

A maior necessidade apontada pelos participantes refere-se ao apoio da gestão, isto é, à institucionalização da política EPS. Os participantes afirmam que, para a EPS ser assumida como uma estratégia de mudança, é preciso que ela seja institucionalizada, pois é preciso garantir um espaço institucional para assegurar a sustentabilidade dessa política (MENDONÇA, NUNES, 2011, p. 879).

Observa-se ainda que, um estudo que tinha como escopo as ações de EPS da Atenção Básica no Mato Grosso do Sul, mapeou que cerca de 70\% das equipes envolvidas informaram ter apoio Institucional para tais ações [A9], entretanto, foi observado que equipes da Capital do Estado relatavam mais apoio que as equipes do interior, sendo observada correlação entre as ações da gestão e sua influência na organização do processo de trabalho das equipes [A9].

Vale salientar ainda que, o apoio organizacional é compreendido em muitos estudos 
[A6, A10, A12, A15, A16, A18 e A20] como a alocação de recursos financeiros e materiais Organização. Acerca do entrave da gestão financeira da EPS, A12 explana que:

A gestão de recursos financeiros ainda se configura como um desafio a ser superado na realidade da educação permanente em saúde, pois não há como manter uma ação continuada de processos de mudança se os aspectos relativos ao financiamento ainda se configuram como um entrave (FERRAZ et al, 2013, p. 1692).

Sob outra perspectiva, o estudo A19 observa que os sujeitos entrevistados:

Expressam que este investimento deve ser compartilhado tanto pela instituição, ao proporcionar oportunidades de aprendizagem, quanto pelos próprios profissionais que precisam, também, buscar outros cenários de aprimoramento profissional e de autodesenvolvimento (LIMA, KURCGANT, 2009, p. 236).

Um estudo versa também sobre a falta de clareza existente para seus participantes entre as concepções de apoio institucional e de ECS/EPS, sendo que os entrevistados de Coelho e Silva et al [A2] trataram o apoio institucional como sinônimo de educação permanente, apagando nuances existentes entres dois conceitos.

É possível identificar, ainda, outras questões relacionadas a dificuldade em se apoiar institucionalmente a EPS: custo das ações [A15], atraso na disponibilização, burocratização e dificuldade de operacionalização da descentralização no repasse financeiro [A6], pouca priorização da EPS pela gestão ocasionada pela falta de resultados imediatos das ações [A10] e resistência dos gestores à quebra de paradigma para a formação de trabalhadores críticoreflexivos $[\mathrm{A} 13, \mathrm{~A} 14]$.

\section{ECS/EPS COMO INSTRUMENTO DE GESTÃO}

Convergentemente, as pesquisas inclusas nesta revisão consideravam a ECS/EPS como parte dos processos que integram a Gestão em Saúde, e em especial a Gestão de Pessoas [A4, A7-A11, A16 e A19]. Esta concepção não é unânime, mas é recorrente na amostra, assim como A7 expressa não ser uníssono entre seus participantes: "Embora não seja unânime entre os municípios desta região, aparece de forma bastante clara a perspectiva da EPS como ferramenta de gestão no nível local" (MISHIMA et al, 2015, p. 668).

Sob a perspectiva das fontes de demandas de EPS foi vista que tanto a capacitação técnico-científica, as necessidades sentidas pelo supervisor da equipe, as dificuldades apontadas para lidar com os usuários e na execução do cuidado quanto as necessidades vislumbradas pela Gestão são motrizes das ações [A10].

É observada também a necessidade de proximidade dos gestores aos projetos de ECS/EPS [A7]. As ações educativas foram entendidas ainda, como espaços para a qualificação das relações interpessoais [A10, A11] e o empoderamento do trabalhador [A7], consolidandose como espaços de discussão [A7, A8, A10, A14]. Outra interface da relação com a Gestão de 
Pessoas é a perspectiva de que para a institucionalização da EPS é preciso a análise dos reflexos deste processo sobre a prática e indicadores de saúde [A16].

Nesta categoria temática, é necessário ainda versar acerca da própria conformação da EPS e os conceitos de autoanálise e autogestão [A9] que estão embutidos nesta concepção educativa. A problematização do contexto de trabalho, inerente à EPS torna-se, por si só, um instrumento gerencial poderoso. Assim, quanto mais alinhada ao processo de gestão, mais resultados da EPS serão implementados no contexto de trabalho. De forma inversa, os resultados são comprometidos se desalinhada aos interesses estratégicos, conforme exemplifica e excerto de A20 a seguir: "No entanto, os conhecimentos adquiridos nem sempre foram implementados, em razão dos problemas organizacionais e gerenciais existentes" (MUROFUSE et al, 2009, s/p).

\title{
POLÍTICAS DE GESTÃO DE PESSOAS
}

Os resultados das pesquisas delimitadas pela amostra [A2, A3, A17 e A22] perpassaram algumas iniciativas e Políticas Públicas de Saúde do SUS. Foram identificadas as seguintes iniciativas, programas e Políticas Públicas: A Política Nacional de Educação Permanente em Saúde (PNEPS); Sistema Universidade Aberta do SUS (UNA-SUS); Programa de Melhoria do Acesso e Qualidade (PMAQ); Pactos pela Vida e de Gestão; e Programa de Aprendizagem a Distância em Recursos Humanos em Saúde (PADRHUS).

Acerca da integração dos projetos de EPS ao PNEPS, A17 reforça que:

\begin{abstract}
A integração de todos os processos de capacitação e desenvolvimento de recursos humanos à política de educação permanente é de responsabilidade conjunta de todos os gestores, respeitando, cada qual, o respectivo âmbito de gestão no SUS. No entanto, ao gestor municipal, a integração conjunta dos processos de educação permanente em saúde se estende diretamente ou em cooperação com o gestor estadual, com os municípios da região e com a união. A formulação de políticas de regulação e de indução de mudanças no campo da graduação e da especialização das profissões de saúde constitui uma ação que envolve os gestores federal e estadual. 0 primeiro com a responsabilidade de propor e pactuar; e o segundo, de articular e participar (ANDRADE, MEIRELLES, LAZONI, 2011, p. 376).
\end{abstract}

Neste sentido, torna-se de suma importância reconhecer a EPS como Política Pública e conhecer as esferas de atuação gerencial para aumentar a visibilidade e possibilitar uma avaliação dos processos de gestão e execução das ações em cada nível de atuação. (ANDRADE, MEIRELLES, LAZONI, 2011).

Vale ressaltar, neste momento da discussão, que nenhum trabalho foi encontrado no contexto da Saúde Suplementar. 


\title{
EMERSÃO DA SAÚDE DO TRABALHADOR ATRAVÉS DA ECS/EPS
}

Torna-se relevante também a associação do sucesso ou insucesso das ações de ECS/EPS com características do processo de trabalho. Em alguns contextos é explicito que o desgaste vivido pelo trabalhador da saúde [A20], a sobrecarga de trabalho [A15], a falta de motivação [A15], a rotatividade [A8] e a falta de estabelecimento de vínculo entre os membros da equipe [A8] são fatores que dificultam a operacionalização dos processos de educação em saúde.

Em alguns momentos, é possível observar a associação direta entre a baixa adesão aos programas de ECS/EPS e algumas das características descritas acima, conforme expressa o excerto a seguir:

\begin{abstract}
A chefia do DEPE, ao avaliar as capacitações efetuadas no período em estudo e a baixa frequência dos participantes, detectou alguns problemas relacionados a não participação dos servidores nas atividades de capacitações, ocasionando inclusive o cancelamento de treinamentos e eventos, devido a pouca adesão dos mesmos. Os motivos para a situação descrita acima se fundamentam na falta de recursos humanos nas unidades, na sobrecarga de trabalho e na falta de motivação das chefias (COSTA et al, 2012, p. 263-4).
\end{abstract}

Consequentemente, os resultados das ações de ECS/EPS são influenciados pelas características de precarização do trabalho que assolam o trabalho em saúde.

Sob outra perspectiva, é possível também compreender os espaços criados por estas ações como promotores de Qualidade de Vida dos trabalhadores de Saúde, conforme discutido em A21:

\begin{abstract}
Desta forma, acredita-se que as instituições de saúde possam constituir-se como espaços destinados a favorecer o crescimento pessoal e profissional, bem como contribuir para a qualidade de vida dos trabalhadores da saúde ao reconhecê-los como sujeitos de sua própria história (FERRAZ et al, 2006).
\end{abstract}

\section{CONSIDERAÇÕES FINAIS}

Este estudo identificou a influência da educação continuada ou educação permanente em saúde na Gestão de Pessoas nos Serviços de Saúde brasileiros. Avança no conhecimento científico por compreender que há influência da ECS/EPS na Gestão de Pessoas, sendo identificado que, para além do objetivo idiossincrático de desenvolver pessoas outros domínios, como a saúde do trabalhador, também podem ser influenciados direta ou indiretamente pelo processo de ensino-aprendizagem ou resultados das ações educativas.

Observou-se que a produção do conhecimento sobre esta temática tem aumentado discretamente, com destaque para a perspectiva da EPS, assim como a Gestão de Pessoas, em compreender o trabalhador no contexto de trabalho como o foco das ações educativas. Desta maneira, o apoio Institucional emergiu como ponto nevrálgico para o sucesso das ações de 
ECS/EPS, podendo ele atuar tanto como potencializador quanto como desafio importante para a manutenção e qualidade das ações. Além disso, as ações educativas são descritas como parte integrante da Gestão de Pessoas e, no cenário público, como parte das Políticas Públicas em Educação e Gestão. Deste modo, o envolvimento ativo do gestor como facilitador se torna indispensável para alinhar os objetivos das ações desenvolvidas aos objetivos estratégicos, táticos e operacionais da Gestão de Pessoas.

Este estudo limita-se metodologicamente ao se caracterizar por uma revisão integrativa de literatura, não tendo o caráter compreensivo extensivo de outros métodos de revisão como a revisão sistemática de literatura. Desta forma, identifica-se como limitações a análise apenas da realidade brasileira, não extrapolando para uma discussão de cunho internacional. Também, pode ser visto como um possível viés a não identificação de estudos que tivessem como cenário a saúde suplementar brasileira. Sabe-se que o processo de gestão de pessoas no cenário público tem diferenças substanciais ao do setor privado e estas diferenças não foram discutidas nesta pesquisa. Sugere-se, assim, o incentivo à novas pesquisas no campo do desenvolvimento de pessoas, em ambos cenários, para qualificar a gestão de pessoas nos diversos contextos das instituições de saúde brasileiras.

\section{REFERÊNCIAS}

ADORNO, Alexandrina Maria Nogueira Guerra et al. Gestão hospitalar como ferramenta do cuidado. Rev. enferm. UFPE on line, Pernambuco, v. 11, n. 8, p. 3143-50, 2017. Disponível em: $<$ https://periodicos.ufpe.br/revistas/revistaenfermagem/article/view/110220/22135>Acesso em 08 abr. 2019.

ANDRADE, Selma Regina; MEIRELLES, Betina Hörner Schlindwein; LAZONI, Gabriela Marcellino de Melo. Educação permanente em saúde: atribuições e deliberações à luz da Política Nacional e do Pacto de Gestão. Mundo saúde, São Paulo, v. 35, n. 4, p. 373-381, 2011. Disponível em:

<http://bvsms.saude.gov.br/bvs/artigos/educacao_permanente_saude_atribuicoes_deliberac o_pacto_gestao.pdf>. Acesso em 08 abr. 2019.

BRASIL. Ministério da Saúde (MS). Secretaria-Executiva. Secretaria de Gestão do Trabalho e da Educação na Saúde. Glossário temático: gestão do trabalho e da educação na saúde. Brasília: Editora do Ministério da Saúde; 2009.

BRASIL, Lina Sandra Barreto; HADDAD, Ana Estela. O modelo pedagógico da universidade aberta do sus e o seu alinhamento com a educação permanente e as competências profissionais em saúde. EmRede: Rev. Educ. a Dist., Rio Grande do Sul, v. 4, n. 1, p. 38-51, 2017. Disponível em:

<https://www.aunirede.org.br/revista/index.php/emrede/article/view/243/254>. Acesso em 04 abr. 2019. 
CARDOSO, Ivana Macedo. "Rodas de educação permanente" na atenção básica de saúde: analisando contribuições. Saúde Soc, São Paulo, v. 21, n. 1, p. 18-28, 2012. Disponível em: <http://www.scielo.br/pdf/sausoc/v21s1/02.pdf>. Acesso em 08 abr 2019.

COELHO E SILVA, Lais Marques et al. Implementação do Programa de Melhoria do Acesso e Qualidade segundo gestores da Atenção Básica de São Paulo. Acta paul. enferm., São Paulo, v. 30, n. 4, p. 397-403, 2017. Disponível em: <http://www.scielo.br/pdf/ape/v30n4/0103-2100ape-30-04-0397.pdf>. Acesso em 08 abr. 2019.

COSTA, Daniele Bernardi da et al. Custo de educação continuada para equipe de enfermagem de um hospital universitário público. Rev. eletrônica enferm., Goiás, v. 14, n. 2, p. 257-66, 2012. Disponível em: <https://www.fen.ufg.br/revista/v14/n2/v14n2a05.htm>Acesso em 08 abr. 2019.

DUARTE, Maria de Lourdes Custódio; OLIVEIRA, Aládia Inês de. Compreensão dos coordenadores de serviços de saúde sobre educação permanente. Cogitare enferm., Paraná, v. 17, n. 3, p. 506-12, 2012. Disponível em: <https://revistas.ufpr.br/cogitare/article/view/29292/19042>. Acesso em 08 abr. 2019.

FALKENBERG, Mirian Benites el al. Educação em saúde e educação na saúde: conceitos e implicações para a saúde coletiva. Ciência \& Saúde Coletiva. Rio de Janeiro, v. 19, n.3, p. 847852, 2014. Disponível em: <http://www.scielo.br/pdf/csc/v19n3/1413-8123-csc-19-0300847.pdf>. Acesso em 08 abr. 2019.

FERRAZ, Fabiane et al. Gestão de recursos financeiros da educação permanente em saúde: desafio das comissões de integração ensino-serviço. Ciênc. saúde coletiva, Rio de Janeiro, v. 18, n. 6, p. 1683-93, 2013. Disponível em: <http://www.scielo.br/pdf/csc/v18n6/20.pdf>. Acesso em 08 abr. 2019.

FERRAZ, Fabiane et al. Educação permanente no trabalho como um processo educativo e cuidativo do sujeito-cuidador. Rev Gaucha Enferm., Rio Grande do Sul, v. 27, n. 3, p. 344-50, 2006. Disponível em:

<https://seer.ufrgs.br/RevistaGauchadeEnfermagem/article/view/4622/2634>. Acesso em 08 abr. 2019.

FIGUEIREDO, Eluana Borges Leitão de et al. The Pororoca effect on permanent education in health: about the interaction research-work. Rev. Bras. Enferm., Brasília, v. 71, n. 4, p. 176873, 2018. Disponível em: <http://www.scielo.br/pdf/reben/v71s4/pt_0034-7167-reben-71-s41768.pdf>. Acesso em 08 de abr. 2019.

LIMA, Sayonara Arruda Vieira; ALBUQUERQUE, Paulette Cavalcanti; WENCESLAU, Leandro David. Educação Permanente em saúde segundo os profissionais da gestão de Recife, Pernambuco. Trab. Educ. Saúde, Rio de Janeiro, v. 12, n. 2, p. 425-441, 2014. Disponível em: Disponível em: <http://www.scielo.br/pdf/tes/v12n2/a12v12n2.pdf>. Acesso em 08 de abr. 2019.

LIMA, Antônio Fernandes Costa; KURCGANCT, Paulina. Indicadores de qualidade no 
gerenciamento de recursos humanos em enfermagem. Rev Bras Enferm., Brasília, v. 62, n. 2, p. 234-9, 2009. Disponível em: <http://www.scielo.br/pdf/reben/v62n2/a10v62n2.pdf>. Acesso em 08 de abr. 2019.

MACHADO, Jacinta de Fátima Franco Pereira et al. Educação Permanente no cotidiano da Atenção Básica no Mato Grosso do Sul. Saúde debate, Rio de Janeiro, n. 39, n. 104, p. 102113, 2015. Disponível em: <http://www.scielo.br/pdf/sdeb/v39n104/0103-1104-sdeb-39-10400102.pdf>. Acesso em 08 de abr. 2019.

MCHUGH, Mary L. Interrater reliability: the kappa statistic. Biochem Med., Croácia, v. 22, n. 3, p. 276-82, 2012. Disponível em: <https://www.ncbi.nlm.nih.gov/pubmed/23092060>. Acesso em 08 abr. 2019.

MEDEIROS, Sandra Marcia Alves; GOUVÊA, Mônica Villela. Gestão hospitalar e educação permanente: um estudo descritivo e exploratório. Rev. enferm. UFPE on line, Pernambuco, v. 11, n. 12, 2017, p. 5150-2. Disponível em:

<https://periodicos.ufpe.br/revistas/revistaenfermagem/article/view/25182/25377>. Acesso em 08 de abr. 2019.

MELNYK, Bernadette Mazurek; FINEOUT-OVERHOLT, Ellen. Making the case for evidencebased practice. In: Evidencebased practice in nursing \& healthcare. A guide to best practice. Philadelphia: Lippincot Williams \& Wilkins, p. 3-24, 2005. Disponível em:

<https://www.ncbi.nlm.nih.gov/pubmed/21162429>. Acesso em 08 de abr. 2019.

MENDES, Karina Dal Sasso; SILVEIRA, Renata Cristina de Campos Pereira; GALVÃO, Cristina Maria. Revisão integrativa : método de pesquisa para a incorporação de evidências na saúde e na enfermagem Integrative literature review : a research. Texto Contexto Enferm., Santa Catarina, v. 17, n. 4, p. 758-64, 2008. Disponível em: < http://www.scielo.br/pdf/tce/v17n4/18. pdf>. Acesso em 08 de abr. 2019.

MENDONZA, Fernanda de Freitas; NUNES, Elisabete de Fátima Polo de Almeida. Necessidades e dificuldades de tutores e facilitadores para implementar a política de educação permanente em saúde em um município de grande porte no estado do Paraná, Brasil. Interface comun. saúde educ., São Paulo, v. 15, n. 38, p. 871-72, 2011. Disponível em:

<http://www.scielo.br/pdf/icse/v15n38/20.pdf>. Acesso em 08 de abr. 2019.

MISHIMA, Silvana Martins. et al. Perspectiva dos gestores de uma região do estado de São Paulo sobre educação permanente em saúde. Rev Esc Enferm USP, São Paulo, v. 49, n. 4, p. 665-673, 2015. Disponível em: <http://www.scielo.br/pdf/reeusp/v49n4/pt_0080-6234reeusp-49-04-0665.pdf>. Acesso em 08 de abr. 2019.

MOHER, David et al. Preferred reporting items for systematic reviews and meta-analyses: the PRISMA statement. BMJ, Reino Unido, v. 9, n. 7, 2009. Disponível em:

<https://www.ncbi.nlm.nih.gov/pmc/articles/PMC2714657>. Acesso em 08 de ab 2019.

MOTTA LINO, Mônica et al. A realidade da Educação Continuada na Enfermagem nos Serviços Públicos de Saúde de Florianópolis. Online Brazilian Journal of Nursing, Santa Catarina, v. 6, n. 
0, p. 75-85, 2007. Disponível em:

<http://www.objnursing.uff.br/index.php/nursing/article/view/619/147>. Acesso em 08 de abr. 2019.

MUROFUSE, Neide Tiemi et al. Diagnóstico da situação dos trabalhadores em saúde e o processo de Formação no polo regional de educação permanente em saúde. Rev Latino-am Enfermagem, São Paulo, v. 17, n. 3, 2009. Disponível em:

<http://www.scielo.br/pdf/rlae/v17n3/pt_06.pdf>. Acesso em 08 de abr. 2019

SANTOS, Adriano Maia dos et al. Desafios à gestão do trabalho e educação permanente em saúde para a produção do cuidado na estratégia saúde da família. Rev. APS, Minas Gerais, v. 18, n. 1, 2015, p. 39-49. Disponível em:

<http://ojs2.ufjf.emnuvens.com.br/aps/article/view/15469/8134>. Acesso em 31 mar. 2019.

SANTOS, Adelcio Machado dos; FRANCO, Suzana Alves de Morais. A administração e o surgimento da gestão de pessoas. Visão, Caçador-SC, v. 7, n. 2, p. 182-191, 2018. Disponível em: <https://periodicos.uniarp.edu.br/visao/article/view/1900/843> Acesso em 05 ago. 2019.

SARDINHA PEIXOTO, Letícia et al. Educação permanente, continuada e em serviço: desvendando seus conceitos. Enfermeria Global, Espanha, v. 29, p. 324-340, 2013. Disponível em: <http://scielo.isciii.es/pdf/eg/v12n29/pt_revision1.pdf>. Acesso em 08 de abr. 2019.

SILVA, Nathália dos Santos et al. Desenvolvimento de recursos humanos para atuar nos serviços de saúde mental. Texto context enferm., Santa Catarina, v. 22, n. 4, p. 1142-51, 2013. Disponível em: <http://www.scielo.br/pdf/tce/v22n4/33.pdf>. Acesso em 08 de abr. 2019.

STRUCHINER, Miriam; ROSCHKE, Maria Alice; RICCIARDI, Regina Maria Vieira. Formação permanente, flexível e a distância pela Internet: Curso de Gestão Descentralizada de Recursos Humanos em Saúde. Pan Am J Public Health, v. 11, n. 3, p. 158-65, 2002. Disponível em: <https://www.scielosp.org/pdf/rpsp/2002.v11n3/158-165/pt>. Acesso em 08 de abr. 2019.

VENDRUSCOLO, Carine et al. A inserção da universidade no quadrilátero da educação permanente em saúde: relato de experiência. Texto context enferm, Santa Catarina, v. 25, n. 1, p. e2530013, 2016. Disponível em: <http://www.scielo.br/pdf/tce/v25n1/0104-0707-tce25-01-2530013.pdf>. Acesso em 31 mar. 2019.

VIEIRA, Ana Paula Mirarchi; KURCGANT, Paulin. Indicadores de qualidade no gerenciamento de recursos humanos em enfermagem: elementos constitutivos segundo percepção de enfermeiros. Acta paul. enferm., São Paulo, v. 23, n. 1, p. 11-5, 2010. Disponível em: <http://www.scielo.br/pdf/ape/v23n1/02.pdf>. Acesso em 08 de abr. 2019.

WHITTEMORE, Robin.; KNAFL, Kathleen. The integrative review : updated methodology. Journal of Advanced Nursing, Reino Unido, v. 52, n. 5, p. 546-553, 2005. Disponível em: <https://onlinelibrary.wiley.com/doi/full/10.1111/j.1365-2648.2005.03621.x>. Acesso em 08 de abr. 2019. 